\title{
Processo Contínuo De Revestimento De Tiras De Aço Por Liga De Alumínio E Zinco
}

\section{Continuous Process For Coating Steel Strips By Aluminum And Zinc Alloy}

\author{
Douglas Santos Pinheiro1; Vandré Albertino Seródio Nascimento2; Willy Costa \\ Veloso3; Luciano Galdino4; Thiago Alexandre Alves de Assumpção5.
}

\begin{abstract}
1. Técnico em Eletrônica Industrial pelo Colégio Albert Einstein. Técnico em Automação Industrial pelo Centro de Educação Profissional e Tecnológica. Graduando em Engenharia de Controle e Automação na Faculdade ENIAC - E-mail: douglas.s.pinheiro@gmail.com

2. Graduando em Engenharia de Controle e Automação na Faculdade ENIAC. - E-mail: vandreserodio@gmail.com

3. Técnico em Eletrônica pelo Colégio Politécnico Ego Sum. Graduando de Engenharia de Controle e Automação na Faculdade ENIAC E-mail:wilcosvel@gmail.com

4. Professor de Física e Elementos de Máquina na Faculdade ENIAC. Mestre em Ciências Exatas e da Terra na área de Física Nuclear pela USP, especializado em Física pela USP e Licenciado em Matemática pela UNG - E-mail: lucianogaldino1@yahoo.com.br

5. Professor de Ciência e Tecnologia dos Materiais na Faculdade ENIAC. Doutor e Mestre em Ciências Exatas e da Terra na área de Microeletrônica (Eng. Elétrica) pela Escola Politécnica da USP e Tecnólogo em Materiais, Processos e Componentes Eletrônicos pela Fatec-SP - E-mail: taa.assumpcao@gmail.com
\end{abstract}

\section{Resumo}

O artigo apresenta a dinâmica do processo contínuo de imersão a quente no revestimento de tiras de aço por liga de alumínio e zinco, baseado no processo da linha Dual Purpose da Companhia Siderúrgica Nacional (CSN), licenciada pela BIEC International Inc. para utilização da liga 55\% Al-Zn (denominada Galvalume ${ }^{\circledR}$ ) no tratamento superficial de aços. São descritos brevemente todas as etapas desse processo, os equipamentos utilizados e como eles atuam para manter o fluxo contínuo, dando ênfase à importante atuação do inversor de frequência que controla a rotação e torque dos motores devido à alteração do raio da bobina quando ela está sendo enrolada e desenrolada. É apresentada também uma dedução matemática para as equações do torque e da rotação em função do número de ciclos efetuados pelo bobinador.

Palavras-chave: Dinâmica; Galvalume; Inversor de Frequência; Tratamento de Superfície.

\begin{abstract}
The article presents the dynamics of the continuous process of hot immersion in the coating of steel strips by aluminum and zinc alloy, based on the process of Dual Purpose line of Companbia Siderúrgica Nacional (CSN), licensed by BIEC
\end{abstract}


International Inc. for using the 55\% Al-Zn alloy (denominated Galvalume ${ }^{\circledR}$ ) in the surface treatment of steel. All the stages of this process, the equipment used and how they do maintain continuous flow are briefly described, emphasizing the important operation of the frequency inverter that controls the speed and torque of the engines due to the coil radius change when it is being coiled and uncoiled. It is also presented a mathematical deduction for torque and rotation equations based on the number of cycles performed by the winder.

Keywords: Dynamics; Galvalume; Frequency Inverter; Surface Treatment.

\section{Introdução}

Existem vários tipos de tratamentos superficiais para o aço, dentre os quais a zincagem, a cromagem, a niquelagem e a estanhagem são alguns exemplos. O tratamento superficial realizado na Companhia Siderúrgica Nacional (CSN) apresenta um diferencial tanto no processo como na composição química. $\mathrm{O}$ processo é contínuo, isto é, as tiras de aço são desenroladas no início do processo, passam por todas as etapas e são enroladas novamente ao final do processo sem nenhuma intervenção de operadores. A composição química do revestimento também é um diferencial, a porcentagem de alumínio na liga é superior ao de uma zincagem convencional.

O objetivo deste trabalho é justamente explicar o processo de revestimento baseado na linha de galvanização contínua, tipo Dual Purpose, da CSN, pois na literatura existem poucas informações sobre a dinâmica desse processo especial. Os trabalhos acadêmicos encontrados focam apenas no processo químico deste tratamento.

Além de apresentar todas as etapas desse processo galvânico, este trabalho destaca os equipamentos utilizados e suas funções, desde o abastecimento do desbobinador efetuado por meio de uma ponte rolante, até a sua saída, destacando os cuidados com relação ao controle de medidas, proteção e armazenamento.

Um destaque especial foi dado ao controle do torque e da rotação do bobinador e do desbobinador através de um inversor de frequência, onde foram apresentadas suas equações em função do número de ciclos efetuados. O sucesso desse processo contínuo se deve à atuação desse dispositivo e ao desenvolvimento das equações que preveem a variação do torque e da rotação, pois só assim é possível manter a velocidade da tira constante durante todo processo. 
2. Processo contínuo no tratamento de superfície por imersão a quente com composição de zinco e alumínio.

Os tratamentos de superfície abrangem a alteração da superfície por meio da transformação química da superfície ou aplicação de revestimentos, além da eliminação de camadas não desejadas (BORGES, 2010).

O processo de revestimento contínuo por imersão a quente para chapas de aço, segundo GalvInfo (2011), possuí mais de cinquenta anos de desenvolvimento para a galvanização (no caso dos revestimentos de zinco). Processos contínuos por imersão a quente são específicos para aços planos; pois não utilizam metais pesados em seu processo e garantem uma camada revestida com acabamento superficial uniforme. A chapa de aço é passada como uma faixa contínua através de um banho de metal fundido à velocidade de até 3,05 metros por segundo $(\approx 600$ pés por minuto).

A Figura 1 apresenta uma parte da técnica utilizada no processo contínuo de imersão a quente para aços planos, onde a chapa é guiada por rolos para ser imergida no banho.

Figura 1 - Técnicas de aplicação por imersão a quente e eletrolítico.

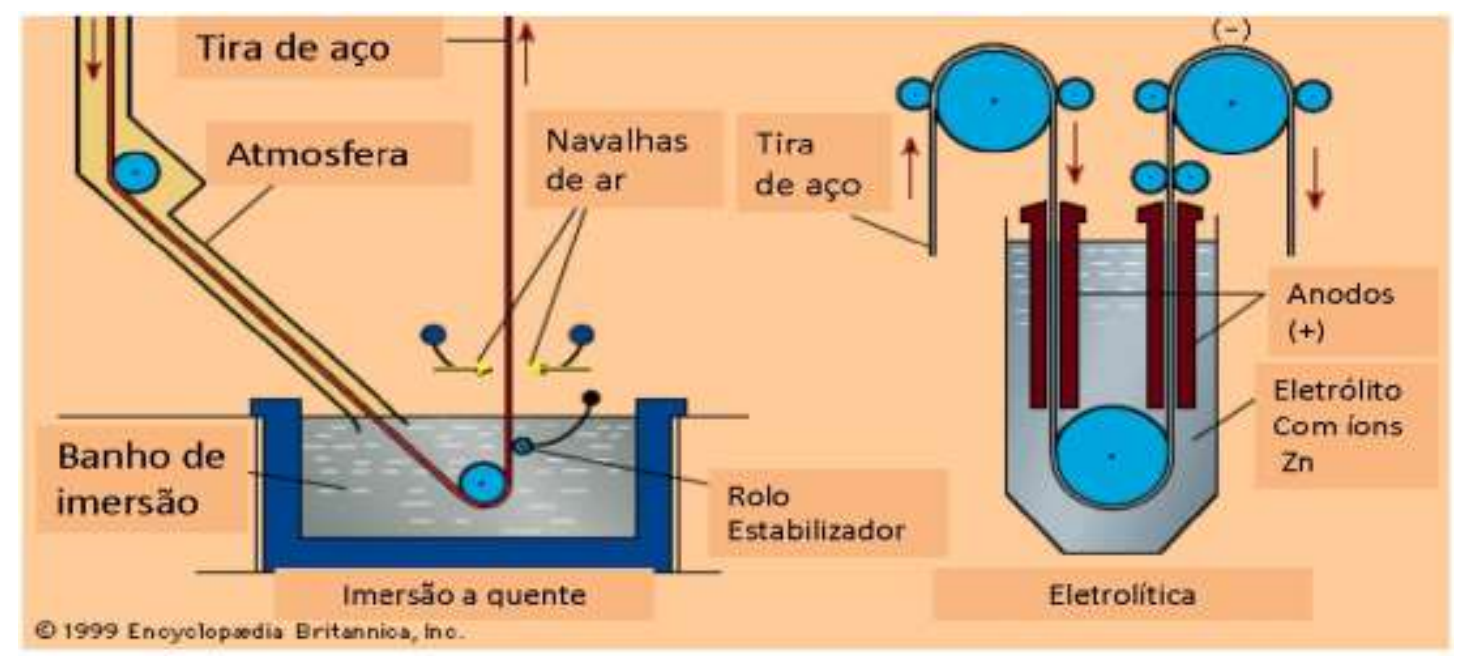

Fonte: Bender e Scheid (2006).

Como o ferro é um metal considerado ativo, é quase sempre necessária a realização de um tratamento de superfície para prevenir a corrosão, usualmente na forma de revestimentos metálicos ou não metálicos, orgânicos ou inorgânicos. O contato direto com a atmosfera ou qualquer outro meio contendo oxigênio ou água, produz no ferro uma forma de corrosão generalizada (vulgarmente chamada de ferrugem) com a formação de camadas de óxidos. A ferrugem é tanto mais intensa quanto mais elevados forem o nível de umidade e de temperatura, podendo ainda ser acelerada pela presença de outros agentes, tais como cloretos, sulfetos e sulfitos, principalmente (TELLES, 1976). 
A empresa Bethlehem Steel Corp realizou, em 1962, um programa de pesquisa com o objetivo de aprimorar o desempenho de aços galvanizados nos mais diversos ambientes, iniciando-se assim a história do Galvalume ${ }^{\circledR}$ (BIEC, 2013).

Após vários ensaios, notou-se que a melhor solução estava na correta proporção de alumínio e zinco no processo galvânico, o que de fato não havia sido experimentado ainda. Num total de doze composições diferentes, com variações de $\mathrm{Al}$ na liga $\mathrm{Al}-\mathrm{Zn}$ entre $0 \%$ e $70 \%$, foi constatada que a composição $55 \% \mathrm{Al}$, $43,5 \%$ Zn e 1,5\% Si ofereceu a melhor combinação para proteção por barreira, sendo que essa pequena adição de silício foi imprescindível para o sucesso do revestimento sobre o aço-base (CSN - Catálogo de Galvanizados).

De acordo com CONI (2004), há registros de outras marcas comerciais desse mesmo revestimento, tais como Aluzinc $($, Algafort ${ }^{\circledR}$, Zalulite ${ }^{\circledR}$, Zincalume ${ }^{\circledR}$, Zincalite ${ }^{\circledR}$, entre outros, porém o revestimento produzidos pela CSN, atualmente autorizado pela BIEC, é chamado de Galvalume ${ }^{\circledR}$. Ainda segundo a CSN os produtos devem atender normas técnicas específicas para sua produção e comercialização. São elas a ASTM A792A, ASTM A924/04, ASTM A924M/97, ASTM A924/97 e NBR 9001.

A introdução comercial do aço Galvalume ${ }^{\circledR}$ foi realizada pela Betblehem Steel Corporation. Posteriormente o produto foi licenciado para empresas siderúrgicas ao redor do mundo, primeiramente na Austrália e Europa, seguido de Ásia e América Latina. (TOWNSEND e BORZILLO, 1997).

\section{Plantas de processamento do tipo Dual Purpose.}

Plantas Dual Purporse, patenteada em 1983 sob o número US 4408561 A, recebe este nome, pois tem proposito de produção de chapas de aços laminadas a frio e chapas de aço galvanizado a quente, além de chapas de aço para estampagem e aço de alta resistência que é endurecida por solução sólida e estrutura de fase dupla, alternando rotas em uma única linha de processamento.

Segundo a patente de número US20100307412 A1 (2010), a instalação do processo de galvanização a quente, para tiras de aço laminada continuamente em movimento, inclui um tanque de revestimento que recebe uma mistura de metal em estado líquido e que contenha, por exemplo, zinco e alumínio a ser depositado sobre a tira que está imersa na mistura, como já destacado na Figura 1. A mistura líquida é distribuída de forma permanente entre o tanque de revestimento e um dispositivo de preparação, sendo a temperatura da mistura líquida deliberadamente reduzida até atingir um limiar de solubilidade no ferro. Essa temperatura deve ser suficientemente elevada para iniciar a fusão de pelo menos um lingote contendo a liga $\mathrm{Al}-\mathrm{Zn}$. 
De acordo com a patente US20030189276 A1 (2003), a instalação de linha Dual Purpose para realização de recozimento e revestimento por imersão a quente continuamente em uma chapa de aço e alternando rotas de processo somente é possível através da instalação de um sistema bypass que conduz a chapa de aço.

Ainda, segundo a patente US20100307412 A1 (2010), a vantagem de uma planta Dual Purpose não é só pelo seu funcionamento como linha de produção de chapa de aço laminado a frio ou como uma linha de produção de galvanização por imersão a quente, mas também a redução do custo de equipamento que poderá ser de 30 a 40\%. Além disso, os custos operacionais fixos, de mão de obra e manutenção, também serão menores.

\section{Linha de produção do Galvalume ${ }^{\circledR}$ da Companhia Siderúrgica Nacional (CSN).}

A linha de galvanização do tipo Dual Purpose foi projetada e desenvolvida com finalidade específica para a produção do Galvalume® e aços galvanizados por imersão a quente (CSN - Catálogo de Galvanizados).

$\mathrm{Na}$ seção de entrada, ilustrada na Figura 2 , ocorre o abastecimento da linha com bobinas de aços laminados a frio para serem revestidos com liga $\mathrm{Al}-\mathrm{Zn}$, os quais são transportados por ponte rolante com capacidade de 25 toneladas. Esse processo é continuo e a tira de aço tem velocidade constante de $120 \mathrm{~m} / \mathrm{min}(2 \mathrm{~m} / \mathrm{s})$.

Figura 2 - Seção de Entrada.

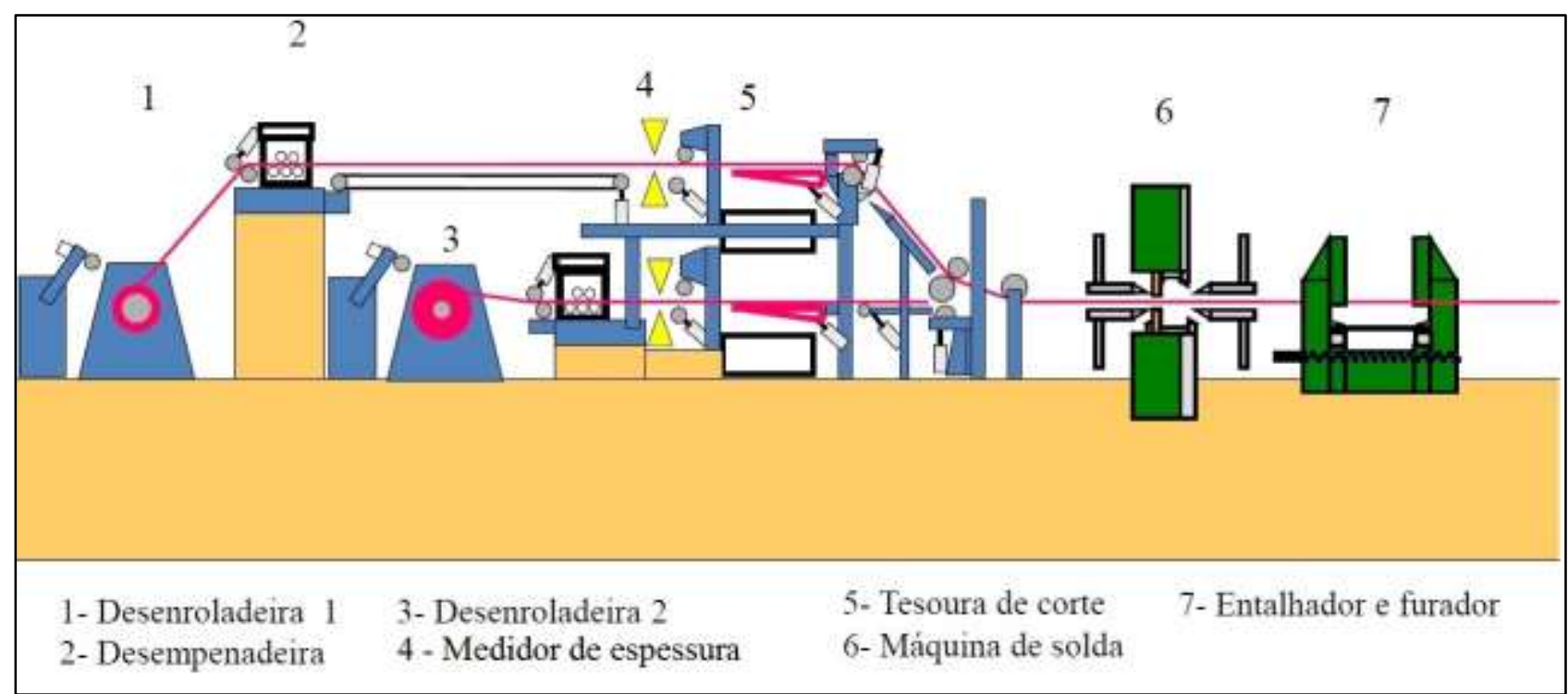

Fonte: Bender e Scheid(2006). 
4.1 Alimentação e controle da linha.

$\mathrm{Na}$ seção de entrada é realizado o abastecimento da linha com bobinas de aço laminado a frio. $O$ controle das medidas, principalmente nas extremidades no início das bobinas e a soldagem do final de uma bobina ao início de outra bobina, garantem a contínua passagem da tira de aço pela linha de galvanização (CSN - Catálogo de Galvanizados).

Para que um desbobinador entre em movimento, faz-se necessária a aplicação de uma força tangencial na chapa para tirá-la da inércia, iniciando assim uma rotação proporcionada pelo torque do motor. A Figura 3 apresenta um exemplo de desbobinador utilizado para desenrolar bobinas de chapas de aço.

Figura 3 - Exemplo de um desbobinador para chapas de aço.

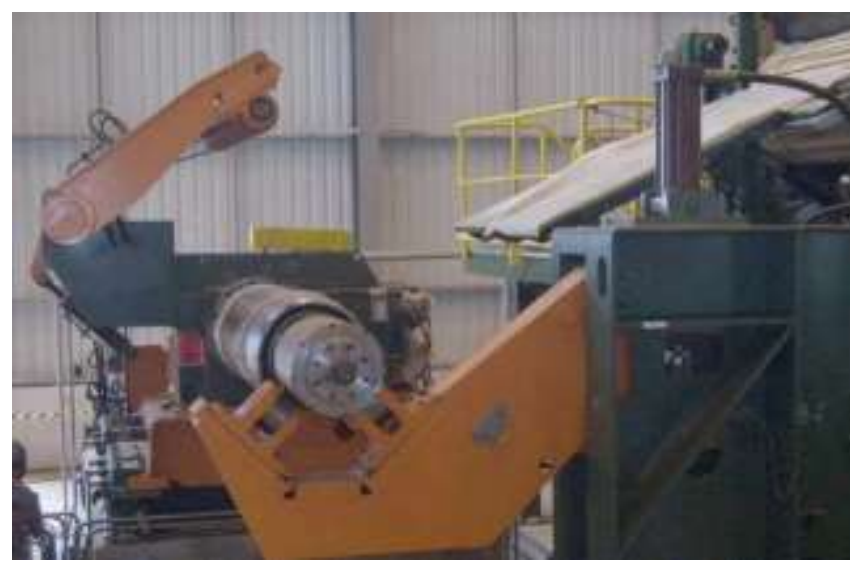

Fonte: Bender e Scheid (2006).

Praticamente todos os motores envolvidos no início do processo, para que a bobina seja desenrolada na seção de entrada e enrolada na seção de saída, são controlados por inversores de frequência.

Segundo Franchi (2008, p. 71) "são inúmeros os motivos e razões para o uso de dispositivos para controle de velocidade. O termo tecnicamente correto para o dispositivo de variação de velocidade é conversor de frequência. $\mathrm{O}$ termo conversor de frequência é empregado por alguns fabricantes, porém a denominação inversor de frequência tornou-se largamente utilizada entre diversos fabricantes e usuários. Inversores de frequência podem ser classificados em quatro tipos básicos de controle amplamente utilizados: escalar (Volts/Hertz), controle vetorial sensorless, controle de fluxo vetorial e controle de campo orientado".

$\mathrm{O}$ inversor de frequência também pode ser considerado como uma fonte de tensão alternada de frequência variável (FRANCHI, 2008, p.59).

Há uma programação que relaciona o diâmetro da bobina com o torque e a velocidade dos drives. É de extrema importância observar o requisito da estabilidade $\mathrm{da}$ velocidade de bobinamento devido às condições impostas pelo material a ser bobinado. Para manter a velocidade do material constante em um bobinador, a rotação do motor será reduzida com o aumento do diâmetro da bobina. Já em um desbobinador, a rotação do motor será aumentada com a diminuição do diâmetro da bobina. (WEG AUTOMAÇÃO). 
A Figura 4 apresenta a geometria de uma bobina, onde possui um raio interno (R1) constante e um raio externo (R2) variável conforme o desbobinamento.

Figura 4 - Representação dos raios externo e interno de uma bobina.

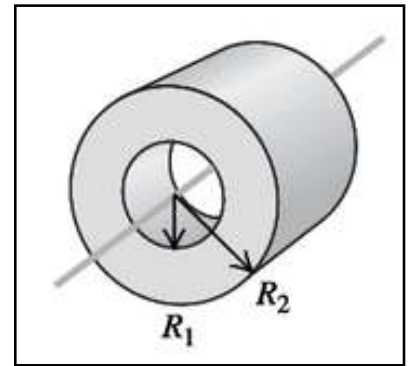

Fonte: Young e Freedman (2008)

Segundo Melconian (2008), o módulo da velocidade angular é diretamente proporcional à rotação (Equação 1).

$\omega=\frac{\pi n}{30}$

E o módulo da velocidade periférica (linear) é dada pela Equação 2.

$v=\omega R$

Substituindo a Equação 1 na Equação 2 e considerando o raio externo $\left(\mathrm{R}_{2}\right)$ como referência chega-se a Equação 3:

$$
v=\frac{\pi n R_{2}}{30}
$$

A cada ciclo $(N)$ percorrido, o raio externo da bobina $\left(\mathrm{R}_{2}\right)$ é diminuído no valor de uma espessura (e) da chapa. Assim obtém-se a Equação 4, a qual determina a rotação em função do ciclo percorrido.

$$
n=\frac{30 v}{\pi\left(R_{2}-e N\right)}
$$

Sendo a aceleração angular $(\alpha)$ definida pela Equação 5 (RESNICK; HALLIDAY; KRANE, 2003).

$$
\vec{\alpha}=\frac{d \vec{\omega}}{d t}
$$

Substituindo a Equação 1 na Equação 5 e sabendo que $n=60 . f$, têm-se:

$$
\alpha=\frac{2 \pi d f}{d t}
$$

Como a frequência é definida como sendo a razão entre o número de ciclos $(N)$ pelo intervalo de tempo (t), chega-se a Equação 6 que representa o módulo da aceleração angular em função do número de ciclos e da rotação:

$$
\begin{gathered}
\alpha=\frac{2 \pi d\left(\frac{N}{t}\right)}{d t} \\
\alpha=\frac{2 \pi N d\left(\frac{1}{t}\right)}{d t} \\
\alpha=-\frac{2 \pi N}{t^{2}}
\end{gathered}
$$




$$
\begin{array}{r}
|\alpha|=\frac{2 \pi f^{2}}{N} \\
|\alpha|=\frac{\pi n^{2}}{1800 N}
\end{array}
$$

A aceleração angular indicada pela Equação 6 terá o sinal negativo (desaceleração) quando se tratar de um bobinador, pois a rotação do motor deve ser diminuída com o aumento do raio. Já para o desbobinador o sinal para aceleração angular será positivo, pois a rotação do motor deverá ser aumentada (aceleração).

Segundo Young e Freedman (2008), o torque $(\boldsymbol{\tau})$ é o produto do momento de inércia (I) pela aceleração angular $(\alpha)$, conforme demonstra a Equação 7.

$$
\vec{\tau}=I \vec{\alpha}
$$

Como a bobina é um cilindro oco, como ilustrado na Figura 4, onde $\mathrm{R}_{1}$ é o raio interno e $\mathrm{R}_{2}$ o raio externo da bobina, o momento de inércia é calculado utilizando-se a Equação 8.

$$
I=\frac{M\left(R_{1}^{2}+R_{2}^{2}\right)}{2}
$$

Como $\mathrm{R}_{2}$ é variável conforme a bobina está sendo desenrolada, a Equação 8 deve ser modificada obtendo-se assim a Equação 9:

$$
I=\frac{M\left[R_{1}^{2}+\left(R_{2}-e N\right)^{2}\right]}{2}
$$

A massa da bobina também vai diminuindo conforme o desenrolamento da bobina. Como a massa é o produto da densidade pelo volume da tira e o volume é o produto da área da base pelo comprimento, então a massa variável pode ser definida em função do número de ciclos $(N)$, dada pela Equação 10:

$$
M=\rho \pi L\left[\left(R_{2}-e N\right)^{2}-R_{1}^{2}\right]
$$

Substituindo a Equação 10 na Equação 9, obtém-se a Equação 11, a qual representa o momento de inércia da bobina em função do número de ciclos:

$$
I=\frac{\rho \pi L\left[\left(R_{2}-e N\right)^{2}-R_{1}^{2}\right]\left[R_{1}^{2}+\left(R_{2}-e N\right)^{2}\right]}{2}
$$

Substituindo as Equações 6 e 11 na Equação 7, encontra-se a Equação 12. Esta equação representa o torque em função do número de ciclos $(N)$ que deverá ser controlado através de um inversor de frequência.

$$
\tau=\frac{\pi^{2} n^{2} \rho L\left[\left(R_{2}-e N\right)^{2}-R_{1}^{2}\right]\left[R_{1}^{2}+\left(R_{2}-e N\right)^{2}\right]}{3600 N}
$$

Vale destacar que o torque apresentado pela Equação 12 está relacionado somente com a bobina que será desenrolada, não leva em consideração o próprio cilindro do 
desbobinador.

\subsection{Seção de pré-tratamento}

Esta etapa (Figura 5) trata-se da seção de limpeza, onde a tira de aço é preparada para ser direcionada ao processo de forno e recozimento.

Nessa secção ocorre inicialmente a limpeza química, localizada antes dos acumuladores, onde se processa a aspersão de desengraxante alcalino sobre o aço seguido de enxágue e secagem por jato de ar em temperatura ambiente. A limpeza eletrolítica ocorre após a passagem pelos acumuladores. O processo consiste na passagem de corrente em solução alcalina entre um polo elétrico e a tira. Após a limpeza eletrolítica, a tira passa pelo processo de limpeza por ação mecânica. Nessa etapa ocorre a passagem por um conjunto mecânico de escovas, seguido por secagem por jato de ar aquecido. A partir deste ponto, o aço está complemente limpo e seco para garantir a aderência dos revestimentos (CSN - Catálogo de Galvanizados).

Figura 5 - Seção de Pré-Tratamento

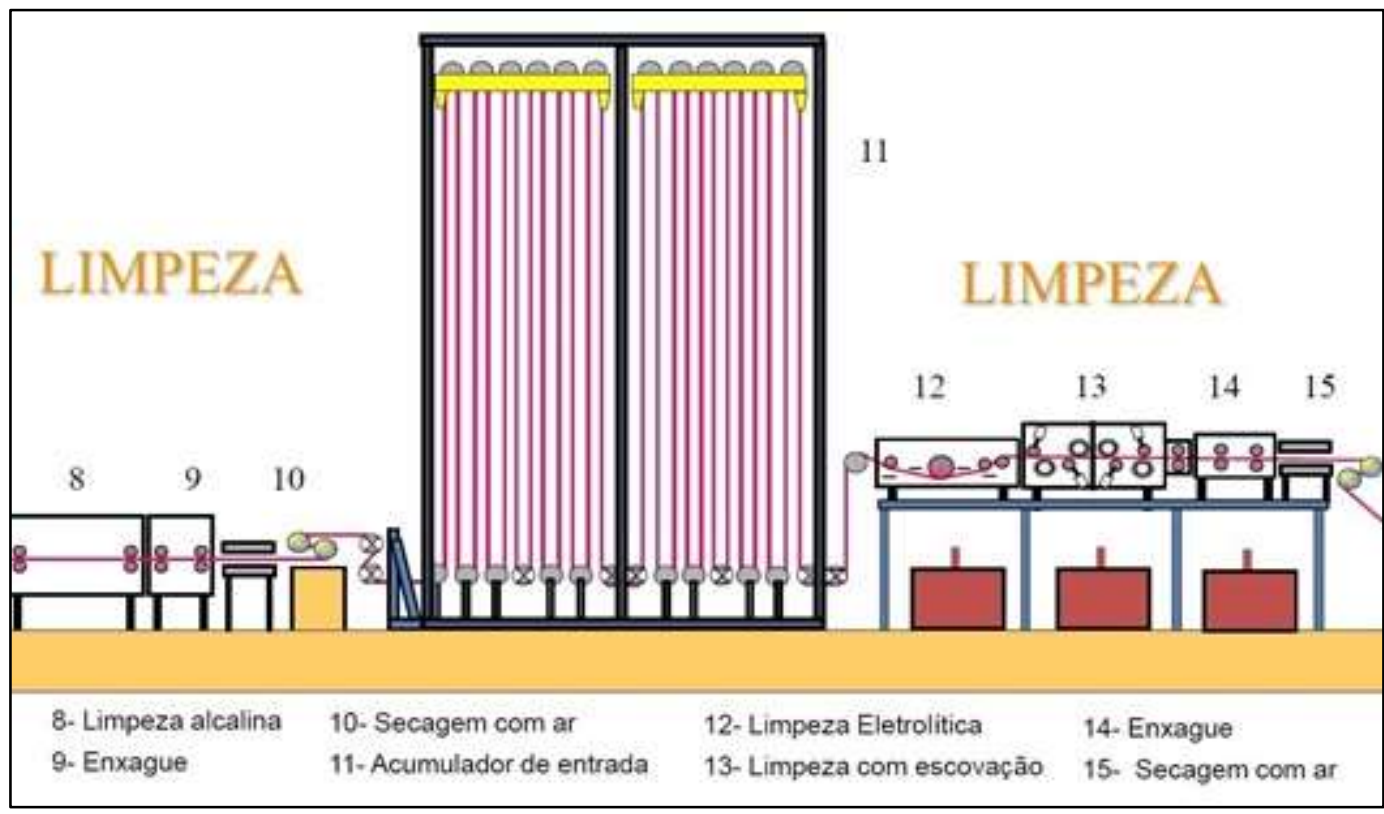

Fonte: Bender e Scheid (2006).

4.3 Seções de processo - forno e revestimento

A Figura 6 destaca as etapas do processo que culminam no revestimento. $\mathrm{O}$ forno de recozimento tem como propósitos fundamentais a evaporação de resíduos oleosos que não tenham sido eliminados em estágios 
anteriores, a remoção de possíveis oxidações por reações com atmosfera redutora, a adequação do aço às propriedades predeterminadas e a preparação da tira para imersão no banho de metal líquido submetendo-a a temperatura adequada.

No pote da liga Al-Zn, conforme item 21 e 22 da Figura 6, após o controle de temperatura, o aço é continuamente guiado por um túnel para imersão, passando pelo pote com a liga fundida, revestindo assim o aço com uma camada metálica.

Após emergir do pote, a massa da camada de revestimento a ser mantida é ajustada com auxílio de um jato de ar fino, funcionando como navalhas de altíssima precisão.

Um resfriamento adicional é requerido, pois garante um produto de melhor resistência à corrosão devido à compensação de temperatura de fusão da liga. (CSN - Catálogo de Galvanizados).

Figura 6 - Seção do Processo Forno e Revestimento.

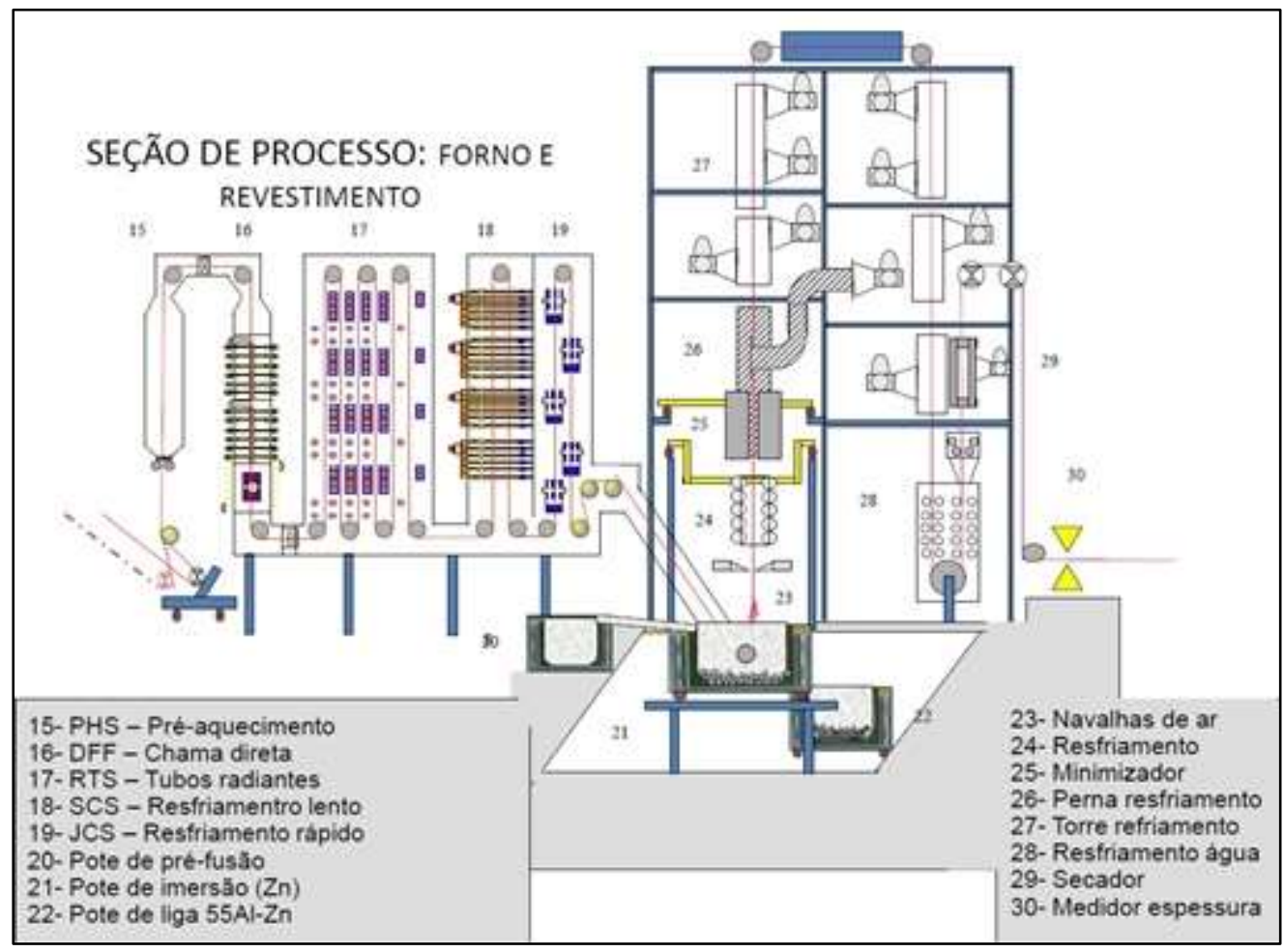

Fonte: Bender e Scheid (2006).

\subsection{Seções pós-tratamento}

As etapas de pós-tratamento são aplicadas à tira de aço com objetivo de manter algumas características específicas do aço com revestimento (CONI, 2004). 
Após seção de resfriamento é feito o processamento do aço junto ao laminador de encruamento (Figura 7) e desempenadeira para melhoria de rugosidade, brilho superficial e melhor qualidade do produto no que se refere às propriedades mecânicas do material recozido e melhoria da aparência superficial (CONI, 2004).
A linha possui dois aplicadores (coaters), conforme Figura 7, em passe vertical, responsáveis pela aplicação de uma película de resina em ambas as superfícies do aço, com finalidade de preservar o aspecto superficial e aumentar a resistência à corrosão do revestimento (CSN - Catálogo de Galvanizados).

Figura 7 - Laminador, rolo tensor e coaters.

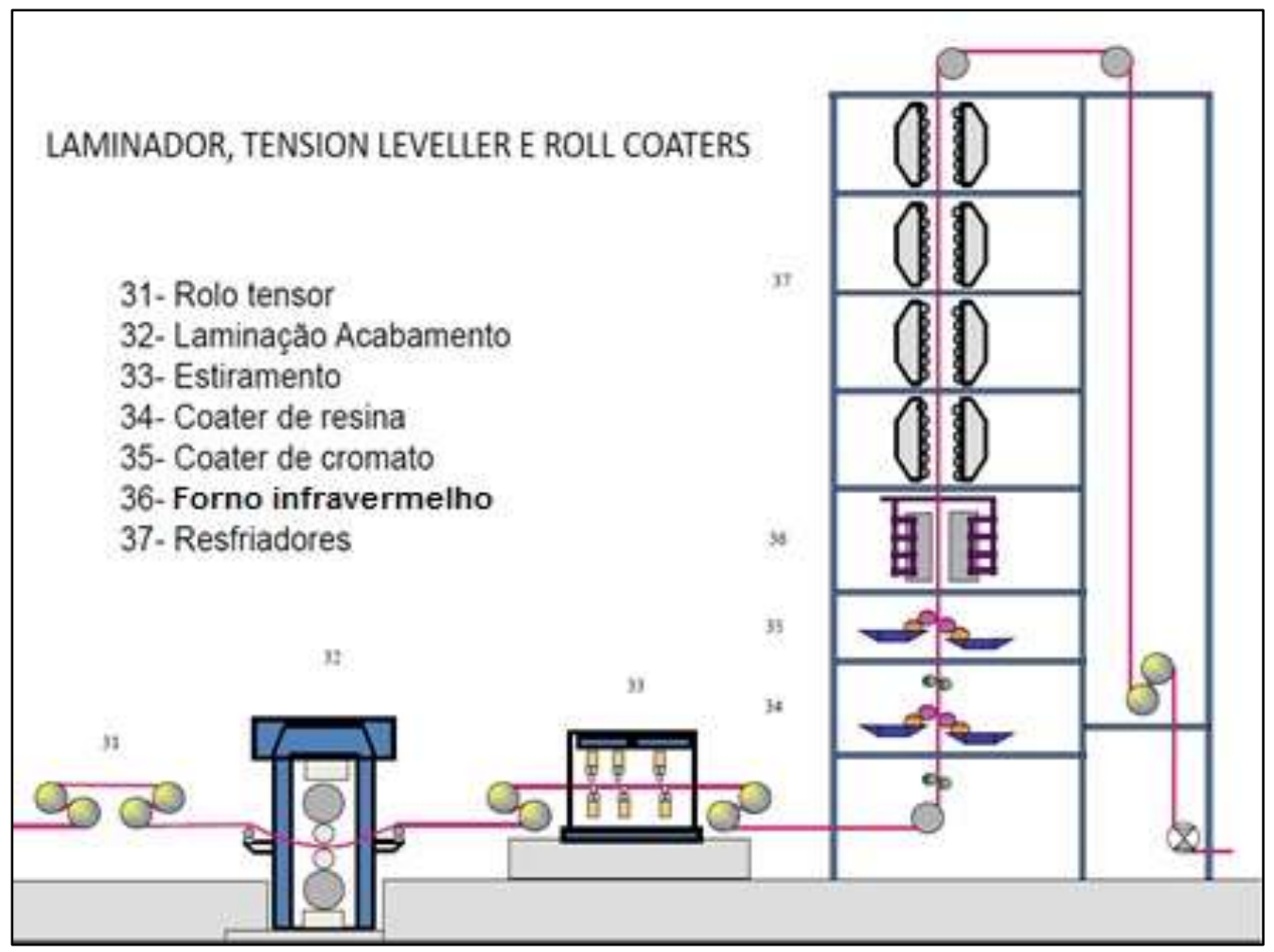

Fonte: Bender e Scheid (2006).

4.5 Seção de saída

Durante o processo de inspeção visual, por inspetores qualificados, a bobina passa por testes dimensionais, de aderência do revestimento e por mediação de rugosidade do aço. $\mathrm{O}$ aço pode finalmente receber filme controlado de óleo protetivo, aplicado por uma oleadeira eletrostática. (CSN - Catálogo de Galvanizados).

Após o processo de inspeção visual, a bobina é enrolada pelas bobinadeiras (Figura 8), 
seguido do corte do aço, pesagem da bobina e, posteriormente, embalagem e armazenamento.

Figura 84 - Seção de Saída

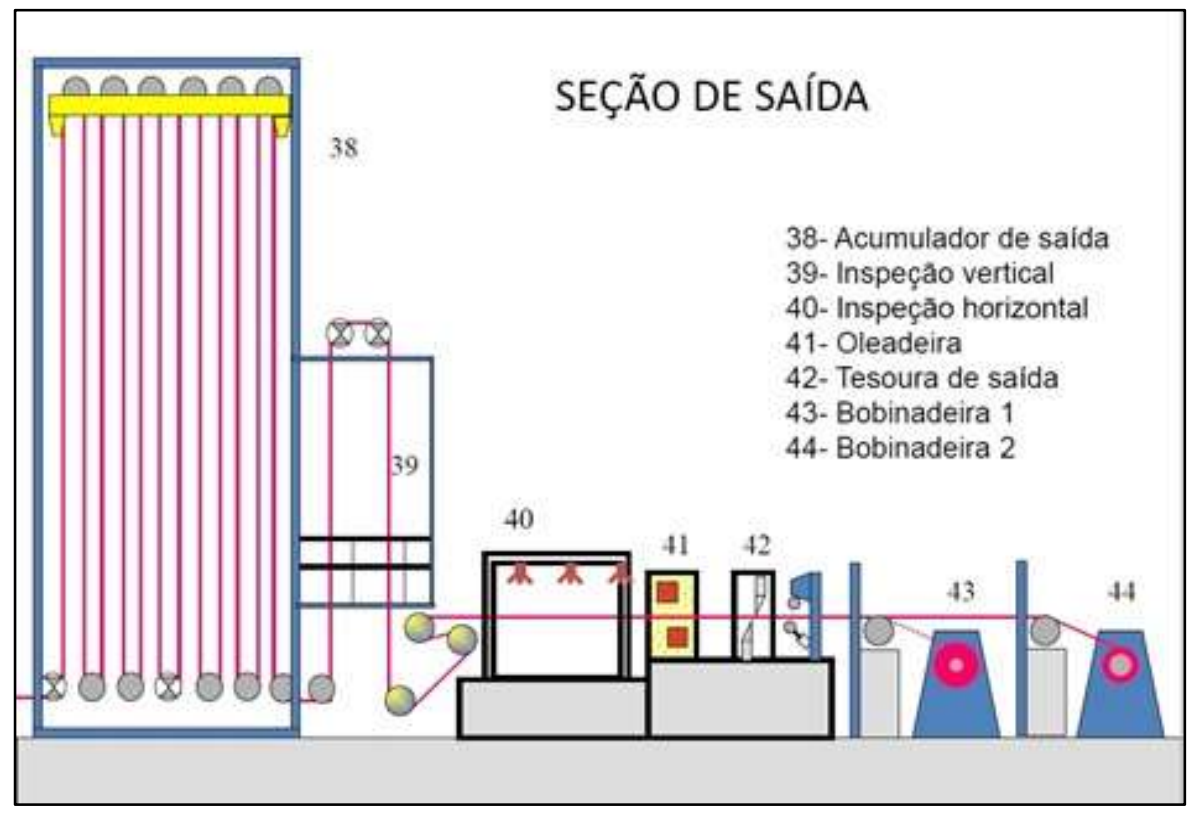

Fonte: Bender e Scheid (2006).

A cada ciclo $(N)$ percorrido, o raio interno da bobina $\left(\mathrm{R}_{1}\right)$ é aumentado no valor de uma espessura (e) da chapa. Assim obtém-se a Equação 13, a qual determina a rotação em função do ciclo percorrido.

$$
n=\frac{30 v}{\pi\left(R_{1}+e N\right)}
$$

O raio externo $\left(\mathrm{R}_{2}\right)$ é variável conforme a bobina está sendo enrolada, isto é, a cada ciclo completo o raio aumenta o valor de uma espessura (e), obtendo-se a Equação 14.

$$
I=\frac{M\left[R_{1}^{2}+\left(R_{1}+e N\right)^{2}\right]}{2}
$$

A massa da bobina também vai aumentando conforme o enrolamento da bobina. Como a massa é o produto da densidade pelo volume da tira e o volume é o produto da área da base pelo comprimento, então a massa variável pode ser definida em função do número de ciclos $(N)$, dada pela Equação 15:

$$
M=\rho \pi L\left[\left(R_{1}+e N\right)^{2}-R_{1}^{2}\right]
$$

Substituindo a Equação 15 na Equação 14, obtém-se a Equação 16, a qual representa o momento de inércia da bobina em função do número de ciclo $(N)$ s: 
$I=\frac{\rho \pi L\left[\left(R_{1}+e N\right)^{2}-R_{1}^{2}\right]\left[R_{1}^{2}+\left(R_{1}+e N\right)^{2}\right]}{2}$

A aceleração angular $(\alpha)$ do bobinador deve estar sincronizada com a do desbobinador, assim a Equação 6 deve ser modificada, isto é, deve-se relacionar o número de ciclos do bobinador com o do desbobinador para que se mantenha a velocidade linear do sistema. A Equação 17 representa a aceleração angular do bobinador nessa aplicação em função do número de ciclos $(N)$ executados. A razão $\frac{R_{2}-R_{1}}{e}$ é o número de ciclos total previsto do desbobinador e $N$ é o número de ciclos que o bobinador está executando na operação.

$$
|\alpha|=\frac{\pi n^{2}}{1800\left(\frac{R_{2}-R_{1}}{e}-N\right)}
$$

Substituindo as Equações 16 e 17 na Equação 7, encontra-se a Equação 18. Esta equação representa o torque em função do número de ciclos $(N)$ que deverá ser controlado através de um inversor de frequência.

$$
\tau=\frac{\pi^{2} n^{2} \rho L\left[\left(R_{1}+e N\right)^{2}-R_{1}^{2}\right]\left[R_{1}^{2}+\left(R_{1}+e N\right)^{2}\right]}{3600\left(\frac{R_{2}-R_{1}}{e}-N\right)}
$$

Vale destacar que o torque apresentado pela Equação 18 está relacionado somente com a bobina que será enrolada, não leva em consideração o próprio cilindro do bobinador.

O tipo de produto, a qualidade superficial requerida e sua forma de transporte e armazenagem definem o tipo de embalagem mais adequada ao produto requerido pelo cliente.

\section{Conclusão}

Neste artigo foi apresentada a dinâmica do processo contínuo do Galvalume ${ }^{\circledR}$ (liga de alumínio e zinco) baseado na linha de produção da Companhia Siderúrgica Nacional (CSN), com foco na atuação dos inversores de frequência usados para controle de torque e rotação.

Foram demonstradas as deduções das equações que determinam a variação do torque e da rotação e que servem de base para a programação dos inversores de frequência com o intuito de se obter um controle da tensão da tira de aço durante o bobinamento e desbobinamento.

\section{Referências Bibliográficas}

BIEC International Inc. Galvalume ${ }^{\circledR}$. Disponível em: <http://www.galvalume.com/galvalume/ index.php?page $=$ product-information $>$. Acesso em: 4 out. 2015. 
BORGES, M. C. C. F. Tecnologia Mecânica

II. 1 ed. São Paulo: Centro Paula Souza ETEC João Gomes Araujo, 2010.

CONI, Nicodemos Henrique da Silva. Estudo das Propriedades Mecânicas do Aço Zincado por Imersão à Quente e Galvalume® Produzido na CSN-PR. 2004. 85 p. Dissertação (Mestrado), Universidade Federal do Paraná, Curitiba, 2004. Disponível em: $\quad<$ http://www.pipe.ufpr.br/portal /defesas/dissertacao/064.pdf $>$.

CSN - COMPANHIA SIDERÚRGICA NACIONAL, Catálogo de Galvanizados. Disponível em: $<$ http://www.csn.com.br/irj/go/km/docs/csn _documentos/CSN/CATALOGO

GALVALUME.pdf>. Acesso em: 16 set. 2015.

FRANCHI, C. M. Inversores de Frequência Teoria e Aplicações. 1 ed. São Paulo: Érica, 2008.

GALVINFO CENTER. Processo de Revestimento e Tratamento de Superfície. O Processo de revestimento Contínuo por Imersão a Quente para Chapas de Aço. São Paulo; v. 2.1, n. Rev 1.0, jan. 2011. Disponível em: $\quad<$ http://www.icz.org.br/galvinfonotes.php>. Acesso em: 15 out. 2015.

MELCONIAN, S. Elementos de máquinas. 9 ed. São Paulo: Érica, 2008.
RESNICK, R.t; HALLIDAY, D.; KRANE, K. S. Física 1. 5. ed. Rio de Janeiro: LTC, 2003.

SCHEID, A., BENDER, W. D., 55\% Al-Zn coated sheet steel (galvalume) - one of the fastest growing steel products. In: $43^{\circ}$ Seminário de Laminação: Processos e Produtos Laminados e Revestidos - ABM, 2006, Curitiba. Anais do Seminário (in press). Curitiba: ABM, 2006. p. 23-33.

TELLES, S. P. C. Materiais para equipamentos de processo. - ed. Rio de Janeiro: Interciência LTDA., 1976.

TOWNSEND, H. E.; BORZILLO, A. R. 55\% Al-Zn Alloy Coated Sheet Steel: The versatile, long lasting building panel steel. In: $5^{\text {th }}$ International Conference on Zinc Coated Steel Sheet, 1997, Birmingham, England. Anais da Conferência. England: BIEC International Inc., $1997 . \quad$ Disponível em: $<$ http://www.steelroofing.com/assets/doc/tec hpaper1.pdf>. Acesso em: 14 set. 2015.

WEG AUTOMAÇÃO. Guia de aplicação para bobinadores - CFW09. 1 ed. Manual de Usuário WEG, jan. 2007. Disponível em: $<$ http:/ / ecatalog.weg.net/files/wegnet/WEGcfw-09-plc-guia-de-aplicacao-para-bobinadoresmanual -portugues-br.pdf $>$. Acesso em: 20 nov. 2015.

YOKOYAMA, H. et. al. Dual-purpose plant for producing cold rolled steel sheet and hot-dip galvanized steel sheet, Nippon Steel 
Corporation, Tokyo, Japan. US Patent \#:

004408561, $1983 . \quad$ Disponível em:

<www.uspto.gov>. Acesso em: 3 out. 2015.

YOUNG, H. D.; FREEDMANN, R. A. Física

I. 12 ed. São Paulo: Addison Wesley, 2008. 